\title{
Antipartidarismo entre as JUVEnTUdes no Brasil, Chile e Colômbia
}

\author{
Rogério de Oliveira ARAÚJO* \\ Olivia Cristina PEREZ**
}

\begin{abstract}
RESUMO: A presente pesquisa faz uma análise comparativa sobre as formas as quais os sentimentos antipartidários se manifestam nas juventudes do Brasil, Chile e Colômbia, países que tiveram grandes protestos com participação dos jovens desde 2011. A percepção desses jovens sobre os partidos políticos foi analisada a partir do banco de dados do Projeto de Opinião Pública da América Latina (Lapop), considerando as ondas de 2006, 2008, 2010, 2012, 2014, 20016 e 2018, com ênfase nos anos de 2010, 2014 e 2018 - períodos marcados por ciclos de protestos nos países selecionados. A classificação dos jovens antipartidários foi feita com base nas variáveis simpatia e confiança pelos partidos políticos. Para entender as percepções dos jovens antipartidários, analisamos o quanto eles apoiam a democracia e se interessam por política. Os resultados demonstram que o antipartidarismo na juventude se manifesta a partir do antipartidarismo reativo relacionado também aos aspectos socioculturais e contextuais.
\end{abstract}

PALAVRAS-CHAVE: Antipartidarismo. Juventude. Democracia. América Latina.

\section{Introdução}

Este trabalho aborda os sentimentos antipartidários nas juventudes latinoamericanas do Brasil, Chile e Colômbia. Estes três países foram palco de intensos protestos nos últimos dez anos, com grande presença de jovens. Não é possível

UFPI - Universidade Federal do Piauí. Programa de Pós-Graduação em Ciência Política. Teresina - PI - Brasil. 64202020 - rogeroliveira373@outlook.com. https://orcid.org/0000-0002-0617-3856.

* UFPI - Universidade Federal do Piauí. Programa de Pós-Graduação em Ciência Política. Teresina - PI - Brasil 64202020 -889oliviaperez@gmail.com.https://orcid.org/0000-0001-9441-7517. 
simplificar as pautas dos protestos que ocorreram, mas sabe-se que elas envolviam desde o reconhecimento de direitos para grupos mais sujeitos a opressões sociais até críticas ao governo e ao sistema político. Contudo, o ponto que interessou a esta pesquisa foi a expressão de sentimentos antipartidários entre os jovens latinoamericanos que residem em países onde aconteceram grandes protestos.

A juventude tem sido objeto de estudo desde o século passado, tendo gerado abordagens conflitantes sobre a definição do que é ser jovem e sobre o período até onde a juventude se estenderia. Neste trabalho adotamos a definição de Boghossian e Minayo (2009), segundo a qual a juventude pode ser compreendida simultaneamente como um momento do ciclo de vida e como um conjunto de condições sociais dos sujeitos. Nesse sentido, referimo-nos às juventudes conscientes de que a definição do que é ser jovem varia entre os países e dentro da mesma sociedade.

Os estudos sobre a juventude dentro da ciência política têm versado especialmente sobre socialização e participação política, procurando compreender: como os jovens formulam suas preferências políticas e se engajam na sociedade e como a perspectiva da tolerância se manifesta nessa faixa etária (KRISCHKE, 2004; FUKS, 2011; BAQUERO; BAQUERO, 2012; RIBEIRO, 2012; OKADO; RIBEIRO, 2015; RIBEIRO; FUKS, 2019); a presença e força da participação dos jovens nos ciclos de protestos recentes (AUGUSTO; ROSA; RESENDE, 2016; GOHN, 2016; PEREZ, 2019) ou os impactos da internet na participação política (BAQUERO; BAQUERO; MORAIS, 2016a; RAMÍREZ, 2016; BAQUERO; MORAIS, 2018).

Estes estudos constatam que as juventudes atualmente tendem a rejeitar os canais institucionais de mediação, em especial os partidos políticos. Por exemplo, de acordo com Baquero, Baquero e Morais (2016a), a partir de uma pesquisa com jovens de Porto Alegre/RS e Curitiba/PR, os jovens associam a política às expressões tais como, corrupção, ladroagem e oportunismo, enquanto os políticos são associados aos termos alienação, corrupção, falsidade e inutilidade. Perez (2019) explica que novas formas de organização política entre os jovens, como os coletivos, compartilham, ao menos discursivamente, de uma forte rejeição às arenas parlamentares, em especial aos partidos políticos. Tais apontamentos nos levaram a questionar sobre o antipartidarismo entre essas juventudes.

A importância dos partidos políticos para os regimes democráticos é um tema central na ciência política. Há estudos seminais como o de Almond e Verba (1989) que se voltam para o papel dos partidos, bem como análises sobre como os sentimentos partidários se desenvolvem ou como a confiança nos partidos impacta a estabilidade das democracias (NORRIS, 1999; MOISÉS 2008; RIBEIRO; CARREIRÃO; BORBA, 2011; BORBA; GIMENES; RIBEIRO, 2015a; FUKS; CASALECCHI, 2016; RIBEIRO; CARREIRÃO; BORBA, 2016; VEIGA et al., 2017; BORBA, GIMENES, RIBEIRO, 2015b). 
Já o antipartidarismo é um fenômeno estudado nas democracias consolidadas desde o século passado, especialmente com o enfoque sobre os motivos que explicam a perda progressiva da centralidade dos partidos para o eleitorado e a identificação das formas como o antipartidarismo é instrumentalizado na ação política para o alcance do poder (BARDI, 1996; POGUNTKE, 1996; POGUNTKE; SCARROW, 1996; VAN BIEZEN; MAIR; POGUNTKE, 2012; DIAS, 2018). No Brasil, as pesquisas sobre rejeição aos partidos políticos são mais recentes e têm seguido principalmente duas linhas explicativas: uma que tende a enfatizar o contexto de formação histórica do país (BAQUERO; LINHARES, 2011; BAQUERO; VASCONCELOS, 2013; FUKS; BORBA; RIBEIRO, 2018; OKADO, RIBEIRO, LAZARE, 2018) e outra que analisa os impactos do refinamento cognitivo sobre as preferências partidárias e sobre a adesão à democracia (RIBEIRO; CARREIRÃO; BORBA, 2011; GIMENES, 2014; GIMENES, 2017; GIMENES; BORBA, 2019). Além disso, estudos como os de Samuels e Zucco (2018) analisam os impactos dos sentimentos partidários sobre o voto no Brasil, evidenciando a importância da compreensão do fenômeno do partidarismo em suas diversas dimensões (partidarismo, apartidarismo e antipartidarismo).

Entretanto, quando nos concentramos na relação entre juventude e antipartidarismo, é perceptível a existência de uma lacuna na literatura. Para preencher essa lacuna, a presente pesquisa apresenta dados sobre as percepções antipartidárias entre jovens de três países da América Latina (Brasil, Chile e Colômbia), analisando em que sentido essas percepções têm se desenvolvido na última década.

Nossa definição de antipartidarismo segue tanto a conceituação de Poguntke (1996), que o define como sentimentos desfavoráveis em relação aos partidos políticos, quanto à intepretação de Fuks, Borba e Ribeiro (2018), que o compreende como um sentimento de extrema rejeição aos partidos políticos. Mas haveria diversos tipos de antipartidarismo. Por exemplo, segundo Poguntke e Scarrow (1996), o antipartidarismo reativo seria o resultado, sobre o eleitor, de contínuas experiências negativas em relação à atuação dos partidos políticos, acompanhadas de um sentimento de rejeição. Já o antipartidarismo cultural seria o resultado do processo histórico de formação das democracias que levaria a uma baixa percepção do eleitor sobre a necessidade de existência dos partidos políticos.

No Brasil, estudos como os de Baquero e Vasconcelos (2013) sugerem que a rejeição aos partidos políticos é um fenômeno relacionado ao contexto histórico do país, no qual o sistema partidário não logrou êxito em se enraizar no eleitorado devido a sua lógica de formação assentada nas elites. Por outro lado, o desenvolvimento de práticas patrimonialistas e o personalismo das campanhas, centradas no candidato e não nos partidos, contribuiriam para essa rejeição aos partidos políticos de um modo generalizado, motivo pelo qual os pesquisadores utilizam o conceito de antipartidarismo cultural de Poguntke (1996). Além disso, estes mesmos pesquisadores sugerem 
que o antipartidarismo cultural seria reforçado pela dinâmica do antipartidarismo reativo, tendo em vista as sucessivas desilusões do eleitorado diante das promessas não atendidas pelos partidos políticos.

A pergunta que guiou esta investigação foi: como os jovens que vivem em países com intensos e recentes ciclos de protestos manifestam sentimentos antipartidários? Para entender o antipartidarismo nas juventudes dos países selecionados, partimos da definição de antipartidarismo reativo e cultural, conforme conceituação de Poguntke e Scarrow (1996). E com o objetivo de averiguar se a rejeição aos partidos se relaciona com apatia política e apreço pela democracia, também investigamos o interesse por política e a preferência pela democracia entre os jovens antipartidários.

Mais detalhadamente, primeiro, apresentamos um panorama dos jovens antipartidários no Brasil, Chile e Colômbia nos anos de 2006, 2008, 2010, 2012, 2014, 2016 e 2018, a partir da junção das variáveis de confiança e simpatia partidária extraídas do Projeto de Opinião Pública da América Latina (Lapop, na sigla em inglês). Depois, examinamos a opinião desses jovens sobre as variáveis de interesse por política e preferência pela democracia, a partir dos anos 2010, 2014 e 2018, considerando o período em que esses países estiveram imersos em ciclos de protestos.

Consideramos que os estudos sobre o antipartidarismo entre as juventudes favorecem a compreensão dos protestos e das organizações políticas contemporâneas - sendo estes dois últimos, ao mesmo tempo, estimulados e estimuladores deste sentimento. Além disso, como afirmam Baquero, Baquero e Morais (2016b), a descrença nos partidos políticos pode levar a um funcionamento precário das próprias normas e leis, abrindo espaço para uma "desinstitucionalização da representação política". Esta é mais uma justificativa para estudar o tema.

Dividimos este trabalho em três seções, além da conclusão. Na primeira, discutimos os estudos sobre o antipartidarismo, focando na percepção política dos jovens. Na segunda seção apresentamos os percursos metodológicos. Na terceira, realizamos uma discussão a partir dos dados do Lapop, procurando explicitar as tendências gerais do antipartidarismo expresso pelos jovens dos países pesquisados (Brasil, Chile e Colômbia). Ao final, apresentamos as contribuições dessa pesquisa para o avanço desse campo de estudos, assim como as possíveis agendas de estudo que se abrem.

\section{Sentimentos partidários negativos e juventudes}

A estabilidade da democracia tem sido um tema caro para cientistas políticos, por isso, há uma profusão de reflexões sobre o que daria sustentação aos regimes democráticos. Dentro desse campo, a figura dos partidos políticos e sua relação 
com o eleitorado são abordadas direta ou indiretamente. Em estudo conhecido, Norris (1999) estabeleceu a importância de se considerar ao menos cinco eixos para compreender o apoio à democracia, dos quais, destacamos a tolerância e o apoio às instituições do regime, no qual se incluem os partidos políticos.

$\mathrm{O}$ apoio à democracia também já foi tema de estudos no Brasil. Por exemplo, ao analisar traços da cultura política brasileira, Moisés (2008) constata o caráter ambivalente do eleitorado, que por um lado revela apoio considerável à democracia e, por outro, rechaça as suas instituições, em especial, as de representação, a exemplo do parlamento e dos partidos políticos. Mais recentemente, Samuels e Zucco (2018) contribuíram com essa discussão em estudo sobre o comportamento eleitoral do Brasil, destacando a importância dos sentimentos partidários para mobilizar o comportamento dos eleitores. Os autores ainda ressaltam a relevância dos sentimentos negativos para a composição do voto dos indivíduos, evidenciando que o antagonismo do eleitor a um determinado partido influencia diretamente nas suas escolhas políticas. Desse modo, conhecer quais partidos o eleitor gosta, quais ele não gosta e como isso influencia seu voto e seu comportamento político, de um modo geral, se tornou uma tarefa necessária e desafiadora para os cientistas políticos (RIBEIRO; CARREIRÃO; BORBA, 2011).

Nas democracias consolidadas a questão da rejeição aos partidos políticos já estava em pauta na década de 1990, quando se buscava entender por que eleitores se afastavam dos partidos (POGUNTKE, 1996; POGUNTKE; SKARROW, 1996). Desse debate deriva a conhecida definição de Poguntke (1996), segundo a qual, o antipartidarismo pode ser compreendido como um conjunto de sentimentos desfavoráveis em relação aos partidos políticos que, segundo ele, se explica pelas mudanças sociais trazidas pela modernidade, tais como, o surgimento das pautas pós-estruturalistas, das novas possibilidades de participação e, também, da mobilização cognitiva. Defendida por Dalton, Mcallister e Wattenberg (2003), a teoria da mobilização cognitiva argumenta que a rejeição aos partidos seria reflexo de um refinamento do eleitor que tende a dispensar mediações em benefício de uma participação mais direta. Dentre outras explicações propostas sobre o tema, o tamanho das democracias foi considerado um fator que se relacionava com a intensidade da participação dos eleitores na vida cívica, enquanto outra leitura ainda propunha a mudança no perfil dos partidos que estariam deliberadamente desinteressados em captar filiados (VAN BIEZEN; MAIR; POGUNTKE, 2012).

No Brasil e na América Latina, apesar de não ser uma temática nova na ciência política, o antipartidarismo tem sido estudado com mais ênfase na última década. $\mathrm{O}$ fenômeno vem sendo estudado em duas vertentes: uma que argumenta sobre a recente democratização dessa região e o pouco tempo que os sistemas partidários tiveram para se institucionalizarem e outra que defende a existência de uma profunda crise do partidarismo que careceria de laços fortes com o eleitorado 
(BORBA; GIMENES; RIBEIRO, 2015a, 2015b). Os sistemas partidários da América Latina não tiveram um desenvolvimento linear, tal como ocorrido nas democracias europeias e norte-americanas; ao contrário, houve não apenas interrupções sucessivas, mas também uma tendência de os partidos já nascerem desligados do eleitorado (BAQUERO; LINHARES, 2011; SAMUELS; ZUCCO, 2018). Aqui, os partidos políticos enfrentam desafios para criar laços junto ao eleitorado, que comumente atribui à maioria dos partidos práticas personalistas, patrimonialistas e de caráter elitista (BAQUERO; VASCONCELOS, 2013; SAMUELS; ZUCCO, 2018).

Logo, o processo de formação das democracias na América Latina e sua consequente relação com os resquícios dos períodos autoritários são pontos importantes para compreender o comportamento político dos atores e suas percepções sobre a democracia e instituições. Nesse sentido, Veiga et al. (2017) salientam a força de fatores como o tempo de existência da democracia e a idade dos indivíduos na avaliação que estes lançam sobre os princípios da democracia e suas instituições de representação. Ao considerar a idade, os autores tomam como hipótese que indivíduos de idade mais avançada, tendo vivido sob regimes autoritários, expressariam um apreço maior pela democracia, enquanto os jovens a vivenciariam como algo quase natural.

Nesse aspecto, o antipartidarismo tem uma relação profunda com a dinâmica da confiança amplamente abordada como fator de estabilidade democrática, como pontua Norris (1999). Entretanto, diferente do que Norris sugere a partir da ideia de um cidadão crítico, a desconfiança observada de maneira generalizada na América Latina estaria mais pautada em um ceticismo gerado pelas más experiências com o funcionamento da democracia (FUKS; CASALECCHI, 2016). Essa percepção corrobora as conceituações de antipartidarismo cultural e reativo apresentadas na introdução deste trabalho: conforme Poguntke e Scarrow (1996), o antipartidarismo reativo seria o resultado de contínuas experiências negativas em relação à atuação dos partidos políticos; enquanto, o antipartidarismo cultural seria o resultado do processo histórico de formação das democracias fortemente marcadas por traços patrimonialistas e personalistas com consequente desenvolvimento de sistemas partidários frágeis.

Ao mesmo tempo em que os partidos parecem não possuir uma capilaridade elevada com eleitorado em geral, eles também enfrentam adversidades com a parcela jovem da população. Desse modo, a estrutura organizativa dos partidos, que já é vista pela população como elitista, tem dificuldades para inserir a juventude e apresenta custos à participação que a maioria dos jovens não pode arcar (OKADO; RIBEIRO, 2015). Como Okado e Ribeiro (2015) salientam, os partidos, em geral, exigem de seus partidários características que não se encaixam em um perfil condizente com o da maioria dos jovens, tanto em relação à disponibilidade de tempo, quanto 
de recursos. Mais do que isso, na estrutura dos partidos, as vozes dos atores são escutadas apenas na medida em que são percebidas como fala de adultos (OKADO; RIBEIRO; 2015). Logo, os jovens teriam pouca possibilidade de inserção de fato nos partidos.

Ainda sobre a relação entre partidos e grupos etários, ao analisar a questão da tolerância política no Brasil, Ribeiro e Fuks (2019) constatam que a idade é um preditor relevante para a escolha dos grupos de rejeição; indivíduos mais velhos tenderiam a rejeitar mais os grupos tradicionais de esquerda, enquanto, os jovens tenderiam a ser politicamente mais progressistas. Os pesquisadores também evidenciaram que esse progressismo da juventude não é absoluto, tendo em vista que no espectro dos valores morais, os jovens possuem uma disposição mais conservadora que se revela na antipatia aos grupos defensores do aborto, por exemplo (FUKS; RIBEIRO, 2019). Essas análises nos dão pistas de como interpretar o antipartidarismo entre os jovens, principalmente porque rompem com estereótipos como o do jovem sempre revolucionário e revelam possíveis motivadores da rejeição a determinados grupos políticos.

A compreensão do desenvolvimento de rejeição aos partidos, por parte dos jovens, caminha com a discussão sobre a socialização política, compreendida como o processo através do qual os atores assimilam suas preferências políticas. A socialização política é comumente analisada sob duas perspectivas diferentes: uma mais rígida, que prioriza a transmissão de preferências e comportamentos políticos de uma geração para outra, e outra, que a considera um processo mais dinâmico, marcado também por influências de contexto, como as crises econômicas ou políticas, ou, ainda, a influência de novas tecnologias (BAQUERO; MORAIS, 2018).

Em relação às novas tecnologias e seus impactos na socialização política dos jovens, parte dos trabalhos tem questionado se os recursos tecnológicos têm promovido uma mudança significativa na cultura política dos jovens (BAQUERO; BAQUERO; MORAIS, 2016a; RAMÍREZ, 2016; BAQUERO; MORAIS, 2018). Por outro lado, a junção de forças da internet e da juventude tem sido apontada como fator explicativo dos grandes e recentes protestos na América Latina. No Brasil, em meados de junho de 2013, o Movimento Passe Livre, formado por jovens estudantes universitários, organizou um protesto na cidade de São Paulo contra o aumento da tarifa de ônibus. Os protestos se espalharam pelo Brasil, marcando o início de um ciclo de confrontos conhecido como Jornadas de Junho de 2013 (PEREZ, 2019). Não é possível associar as Jornadas a um único protesto, pauta ou ator; de fato, as Jornadas reuniram questões de diversas ordens, tanto demandas por direitos sociais, quanto críticas ao sistema político. Parte dos manifestantes, inclusive, foi hostil à presença de partidos e de seus militantes (TATAGIBA, 2014). 
Mas os protestos com grande participação dos jovens e com críticas ao sistema político, em especial aos partidos, não aconteceram somente no Brasil. No Chile, em 2011, a Confederação de Estudantes do Chile (CONFECH) e associações de professores se uniram na convocação de protestos contra o modelo de educação chileno e a favor da educação pública e gratuita para todos (MOYA; GALLARDO, 2019). Em 2019, ocorreu outra série de protestos iniciada por estudantes do ensino médio em resposta ao aumento de preços da passagem do metrô de Santiago, iniciando a onda de protestos que ficou conhecida como Primavera do Chile ou Revoltas no Chile (MOYA; GALLARDO, 2019). Os jovens participantes desses protestos já apresentavam novas formas de ação política que envolviam o uso intensivo de novas tecnologias, a apropriação dos espaços públicos e a promoção de assembleias para a deliberação democrática, reunindo uma série de coletivos que foram definidos por Sandoval Moya e Carvallo Gallardo (2019) como coletivos não-partidários, já que, apesar de possuírem objetivos políticos, esses coletivos não são formados por militantes de partidos políticos tradicionais.

$\mathrm{Na}$ Colômbia, uma onda de protestos em 2019 se contrapôs a um pacotaço de medidas do governo Duque que impactaria as pensões, idade de aposentadoria e salário mínimo dos jovens. Parte importante do público presente nas manifestações era de jovens de universidades públicas e privadas que pediam mais investimentos em educação (BBC, 2019).

Em comum, tais protestos expressavam críticas ao sistema político vigente e contavam com grande presença de organizações que possuem as características daquilo que se denomina coletivos. Embora não seja possível apresentar uma definição rigorosa dos coletivos, já que organizações diversas se assumem desse modo, pode-se afirmar que os coletivos se apresentam como organizações mais fluidas e horizontais. Seus discursos e práticas se opõem às organizações políticas tradicionais, tais como os partidos políticos, por serem consideradas organizações demasiadamente hierárquicas, burocráticas e ineficientes (VOMMARO, 2015; GOHN, 2018; PEREZ, 2019). Embora não sejam recentes, muitos coletivos foram formados depois de grandes protestos, como as Jornadas de 2013, replicando os discursos de oposição às organizações partidárias que marcaram as Jornadas (PEREZ, 2019). Com base nesses estudos, pode-se afirmar que a aversão dos jovens aos partidos políticos é central para a compreensão do seu comportamento nos protestos e das suas formas de organização política.

\section{Procedimentos metodológicos}

Para a presente pesquisa quantitativa, construímos um panorama da avaliação dos jovens sobre os partidos políticos nos países em análise, utilizando os bancos 
de dados do Lapop e considerando as ondas de 2006, 2008, 2010, 2012, 2014, 2016 e 2018. Adotamos o Lapop pela sua periodicidade e abrangência, bem como pelo seu uso em pesquisas sobre sentimentos partidários na América Latina, a exemplo de Gimenes (2017).

A definição do recorte temporal foi pautada em observar a percepção sobre os partidos políticos nas primeiras décadas do século XXI e também levou em conta a ocorrência de manifestações com presença de organizações formadas por jovens e que se colocam mais distantes dos partidos políticos, como os coletivos. Assim, para contemplar esse ciclo que começou em datas diferentes para cada país, consideramos relevante examinar as ondas de 2006, 2008, 2010, 2012, 2014, 2016 e 2018. Trabalhamos as ondas de 2010, 2014 e 2018 com maior ênfase de modo a analisar como a expressão de sentimentos antipartidários tem avançado ao longo desse marcante período de manifestações. Escolhemos Brasil, Chile e Colômbia como os países a serem analisados devido à grande participação de jovens nos protestos nestes países.

É de salientar que os estudos sobre juventude tendem a tomar o recorte etário de 15 a 24 anos como referência, apesar das divergências teóricas sobre o período que a noção de juventude abarca. Nesta pesquisa, no entanto, consideramos o recorte de 16 a 24 anos para compor a amostra devido à composição do survey do Lapop que levou em conta uma amostragem do eleitorado, excluindo, portanto, os menores de 16 anos.

Com base nesse recorte, sistematizamos na Tabela 1 o número de jovens investigados pelo Lapop nos anos de 2006, 2008, 2010, 2012, 2014, 2016 e 2018 no Brasil, Chile e Colômbia e que compõe a amostra abordada no presente estudo. 
Tabela 1: Número de jovens da amostra nos anos em estudo

\begin{tabular}{clrrr}
\hline Anos/Países & & Brasil & Chile & Colômbia \\
\hline \multirow{2}{*}{2006} & Total & 1214 & 1517 & 1491 \\
& Jovens & 268 & 229 & 336 \\
\hline \multirow{2}{*}{2008} & Total & 1497 & 1527 & 1503 \\
& Jovens & 287 & 224 & 352 \\
\hline \multirow{2}{*}{$\mathbf{2 0 1 0}$} & Total & 2842 & 1965 & 1506 \\
& Jovens & 537 & 213 & 359 \\
\hline \multirow{2}{*}{$\mathbf{2 0 1 2}$} & Total & 1500 & 1571 & 1512 \\
& Jovens & 289 & 179 & 349 \\
\hline \multirow{2}{*}{$\mathbf{2 0 1 4}$} & Total & 1500 & 1571 & 1512 \\
& Jovens & 305 & 179 & 349 \\
\hline \multirow{2}{*}{$\mathbf{2 0 1 6}$} & Total & 1532 & 1625 & 1563 \\
& Jovens & 344 & 252 & 276 \\
\hline \multirow{2}{*}{$\mathbf{2 0 1 8}$} & Total & 1498 & 1638 & 1663 \\
& Jovens & 337 & 271 & 319 \\
\hline
\end{tabular}

Fonte: Elaboração própria com base nos dados do Lapop, 2006, 2008, 2010, 2012, 2014, 2016, 2018.

Tendo em vista a dificuldade em se definir quem são os antipartidários, ou seja, aqueles indivíduos que rejeitam as legendas partidárias, a opção escolhida para gerar nossa amostra nesta pesquisa foi associar as variáveis de confiança e simpatia partidária presentes na base do Lapop. Desse modo, selecionamos os indivíduos que responderam não ter simpatia por nenhuma legenda e, simultaneamente, não ter confiança na atuação dos partidos políticos. Compreendemos que, com esse recorte, selecionamos indivíduos que expressam níveis variados de sentimentos partidários negativos; desde a apatia, passando pelo apartidarismo, até o antipartidarismo propriamente dito. Essa escolha nos permitiu analisar os níveis desses sentimentos partidários negativos e o sentido em que esses sentimentos têm se desenvolvido. Também investigamos o interesse por política e a preferência pela democracia entre os jovens antipartidários, com o objetivo de averiguar se a rejeição aos partidos se relaciona com apatia política e com maior ou menor apreço pela democracia.

\section{Juventude e antipartidarismo na América Latina}

Nesta seção apresentamos um panorama da percepção dos jovens sobre os partidos políticos nos países abordados neste estudo (Brasil, Chile e Colômbia). Inicialmente procuramos comparar a avaliação que os jovens fazem dos partidos políticos, respectivamente, nos anos de 2010, 2014 e 2018, tomando esse recorte para a análise da relação do antipartidarismo com o auge dos ciclos de protestos. 
Gráfico 1: Confiança nos partidos políticos $(\%)$

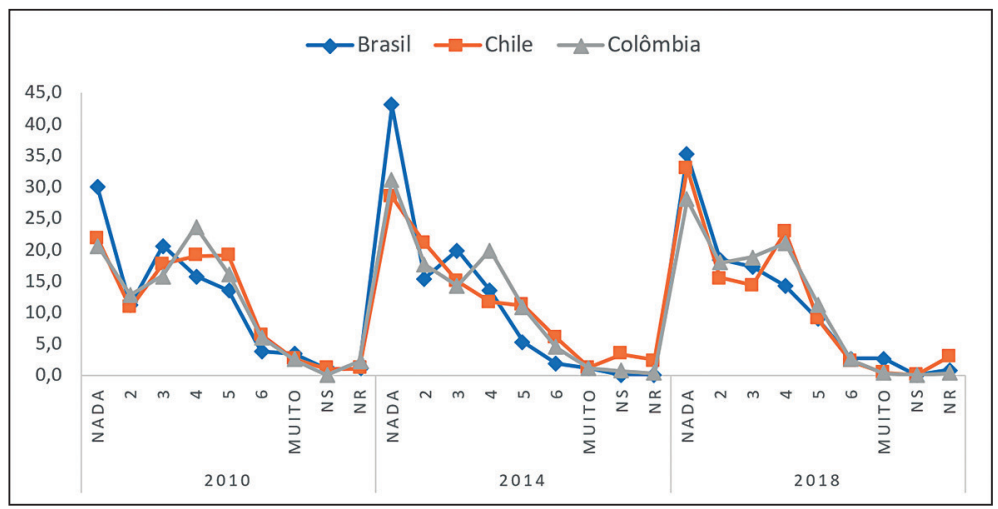

Fonte: Elaboração própria com base nos dados do Lapop 2010, 2014 e 2018.

O Gráfico 1, que trata da confiança nos partidos políticos, mostra a distribuição da percepção dos jovens em relação aos partidos. O ano de 2010 é o momento em que a confiança dos jovens nos partidos políticos esteve maior, mesmo assim, o percentual de nenhuma confiança se manteve entre $20 \%$ e $30 \%$. Em 2014, o aumento na desconfiança é generalizado e ainda mais intenso no caso brasileiro. Já em 2018, observamos uma pequena queda na desconfiança entre os jovens do Brasil e da Colômbia, enquanto no Chile a escalada de crescimento da desconfiança persistiu, alcançando a casa dos $35 \%$.

Apesar dos partidos políticos serem considerados imprescindíveis para o funcionamento da democracia, como salientam Baquero e Vasconcelos (2013), eles não têm logrado um bom desempenho com jovens. Mesmo em períodos de relativa estabilidade política e econômica, como em 2010, os indicadores de confiança permaneceram baixos. O gráfico também demonstra que a percepção dos atores é afetada nos períodos de crise, a exemplo da crise econômica e política que, em 2014, começou a afetar mais fortemente os países pesquisados. $\mathrm{O}$ aumento da desconfiança entre os jovens brasileiros e chilenos, especificamente nos anos 2014 e 2018, evidencia que os partidos, longe de conseguirem cumprir sua função mediadora, foram encarados como parte do problema.

Esse dado remete à percepção de que diferente do que se prega na perspectiva da socialização política, a avaliação sobre as instituições e, em especial, sobre os partidos não são tão rígidas, havendo um peso considerável a ser creditado ao contexto e as experiências que os atores passam (RIBEIRO; CARREIRÃO; BORBA, 2011). Além disso, a desconfiança nos partidos coloca em questão a estabilidade democrática. Como já apresentado por Fuks e Casalecchi (2016), a análise sobre a desconfiança nas instituições tem demonstrado que ela tem se desenvolvido à revelia de um aumento formal de apoio a democracia. 
O caso brasileiro chama a atenção por atingir, nos três anos analisados, os percentuais mais elevados de nenhuma confiança nos partidos políticos entre os três países, chegando à expressiva marca de 42\% em 2014, período em que os protestos iniciados em 2013 permaneciam fortes no território brasileiro. No Chile e na Colômbia, também notamos um aumento da desconfiança nos partidos em 2014 e 2018. Atualmente esses dois últimos países se encontram mais ativos do ponto de vista das mobilizações de rua. Esses dados revelam que existe uma relação entre a percepção dos jovens sobre os partidos e os protestos, os quais podem, por sua vez, evidenciar e intensificar o antipartidarismo.

Tomando como suporte os estudos sobre tolerância/intolerância de Ribeiro e Fuks (2019), podemos compreender melhor o fenômeno de retroalimentação entre protestos e antipartidarismo. A tolerância, conforme os autores, pode ser compreendida como o "acesso ao mercado das ideologias", em outras palavras, a garantia de expressar determinados ideais dentro da sociedade, excluindo-se aqueles que pregam a violência. Dessa forma, o sentimento de intolerância se formaria em vista da sensação de ameaça por determinado grupo (RIBEIRO; FUKS, 2019). Diante disso, os percentuais do gráfico 1 evidenciam como os partidos são encarados sob a ótica da desconfiança, assumindo uma condição de antagonistas para os jovens nos períodos de crise, especialmente aqueles que possuem maior visibilidade e enraizamento no eleitorado, o que facilita a percepção desses atores em sistemas partidários fragmentados (SAMUELS; ZUCCO, 2018).

A incapacidade dos partidos de criarem canais de diálogo com os jovens, especialmente em momentos de crise, leva ao aumento da percepção de que os partidos são instituições "auto promotoras de si" (BAQUERO; LINHARES, 2011). Nesse sentido, a confiança do eleitorado na capacidade de mediação dos partidos tende a cair, o que fragiliza a própria estrutura democrática, já que os partidos têm um papel importante para a estabilidade de um sistema democrático.

Para entender melhor o antipartidarismo, extraímos informações sobre a simpatia dos jovens do Brasil, Chile e Colômbia pelos partidos na última década (ver Tabela 2).

Tabela 2: Simpatia por algum partido (\%)

\begin{tabular}{lccrrrrr}
\hline & \multicolumn{2}{c}{2010} & \multicolumn{2}{c}{$\mathbf{2 0 1 4}$} & \multicolumn{2}{c}{2018} \\
& Sim & Não & Sim & Não & Sim & Não \\
\hline Brasil & 27,4 & 70,2 & 16,5 & 83,5 & 19,3 & 80,4 \\
Chile & 10,8 & 89,2 & 9,9 & 88,5 & 8,1 & 91,1 \\
Colômbia & 32,9 & 66,6 & 26,9 & 72,5 & 18,8 & 80,9 \\
\hline
\end{tabular}

Fonte: Elaboração própria com base nos dados do Lapop 2010, 2014 e 2018. 
Compondo nosso panorama de avaliação da juventude sobre os partidos políticos, a Tabela 2 apresenta o percentual de simpatia partidária. O Chile se destacou em todos os anos com o menor percentual de identificação com algum partido, enquanto o Brasil e a Colômbia apresentaram percentuais altos de simpatia partidária em 2010. O Brasil foi o único país que apresentou leve recuperação da simpatia partidária no ano de 2018, enquanto os demais permaneceram em queda.

A situação econômica e social de 2010 ajuda a entender esses dados, visto que, ao menos no Brasil, mesmo os escândalos de corrupção, a exemplo do mensalão, foram minimizados pelos bons índices de desenvolvimento do país. A América do Sul, em um sentido mais amplo, também não enfrentava grandes consequências econômicas. Diante disso, a expressão da simpatia partidária no Brasil e Colômbia guardam relação com o contexto social.

De acordo com as teorias sobre a socialização política, é esperada uma baixa adesão dos jovens aos partidos políticos, já que as preferências tenderiam a se cristalizar à medida que o indivíduo entra na vida adulta. Segundo a perspectiva de Okado e Ribeiro (2015), a estrutura de organização e a atuação dos partidos também representam uma barreira, à medida que os partidos tendem a dar mais espaço para militantes com um perfil e um estilo de vida adultos.

Os jovens chilenos apresentaram um alto e estável percentual de falta de simpatia por partidos políticos ao longo do período estudado. É importante lembrar que a juventude chilena vem promovendo manifestações e movimentos contra o sistema político com grande força desde 2006, tendo promovido intensos protestos contra o governo em 2011, em especial, para colocar em questão a estrutura de acesso à educação (MOYA; GALLARDO, 2019). Assim, o caso chileno pode ser compreendido como um indicativo para outros países que passam por um contexto político e social semelhante. É interessante notar que os percentuais de rejeição aos partidos vão se equilibrando entre os países estudados à medida que os anos avançam, como se pode ver em 2014 e 2018, o que poderia indicar um período de estabilização, mas que não foi concretizado, dado os protestos chilenos pela Constituinte em 2020.

A seguir, combinamos as variáveis de confiança nos partidos e simpatia partidária para selecionar os jovens com maiores tendências antipartidárias e, em seguida, analisar as percepções desse extrato sobre a política e a democracia. 
Gráfico 2: Jovens com sentimentos partidários negativos (\%)

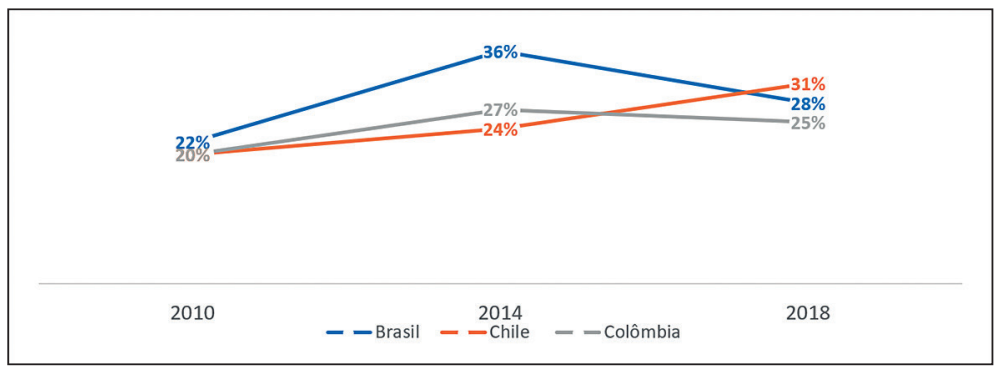

Fonte: Elaboração própria com base nos dados do Lapop 2010, 2014 e 2018.

Como podemos observar no Gráfico 2, os jovens têm experimentado sentimento de rejeição aos partidos políticos desde antes dos grandes ciclos de protestos. Conforme Dias (2018), a dificuldade do eleitor latino-americano em identificar, por uma série de razões, os partidos como atores com existência própria, desvinculada de suas lideranças, impacta diretamente a capacidade de enraizamento dos partidos políticos, fortalecendo, em outra via, o carisma pessoal como fator de influência no voto dos eleitores.

No gráfico 3, essa percepção sobre uma rejeição aos partidos políticos ao longo do tempo pode ser melhor visualizada, além de evidenciar a influência dos acontecimentos na esfera política sobre a percepção dos jovens em relação aos partidos.

Gráfico 3: Jovens com sentimentos partidários negativos entre os anos de 2006 e 2018 (\%)

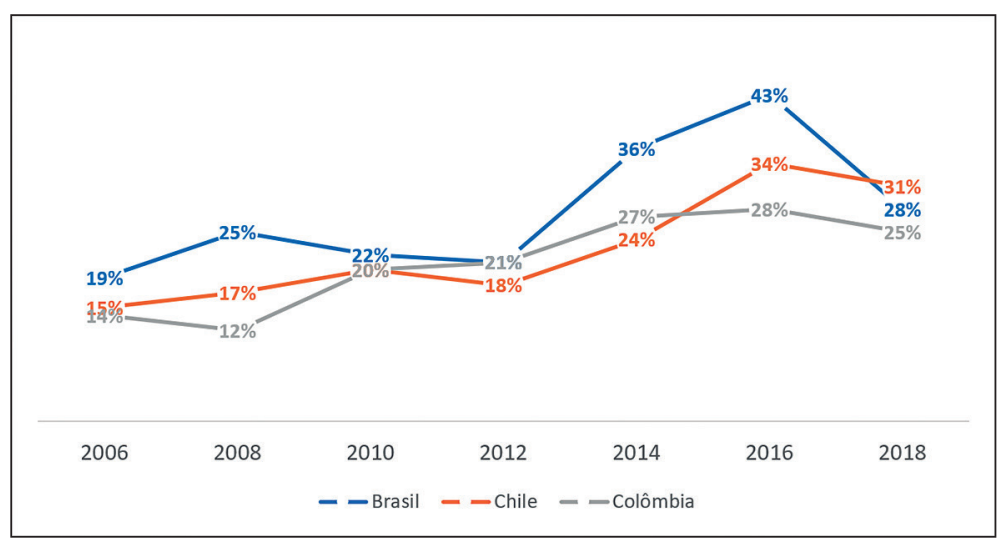

Fonte: Elaboração própria com base nos dados do Lapop de 2006, 2008, 2010, 2012, 2014, 2016, 2018. 
Podemos observar que, quando a aplicação do survey ocorre nos anos marcados por eventos de grande impacto social, há um crescimento da rejeição aos partidos. Assim, tivemos em 2014 e 2016 o ponto alto da expressão de desconfiança e desafeição dos jovens em relação aos partidos no Brasil e Colômbia. Especialmente no Chile, a trajetória de crescimento no número de jovens que expressam uma rejeição acentuada às legendas partidárias foi expressiva entre 2014 e 2016, mantendo-se na casa dos $31 \%$ no ano de 2018 . Neste ano, inclusive, o Chile ultrapassou o Brasil na expressão de sentimentos desfavoráveis aos partidos.

Esses dados têm relação com o cenário de protestos nos países pesquisados. Enquanto os protestos perdiam fôlego no Brasil (o último grande protesto foi o chamado \#Elenão, que se contrapunha à eleição de Bolsonaro em 2018), no Chile eles continuavam em 2020, inclusive com êxitos, como a possível convocação de uma Assembleia Constituinte no país. A Colômbia vive uma segunda onda de protestos em 2020, com milhares de membros de sindicatos, estudantes e indígenas comparecendo às ruas contra as políticas sociais e econômicas do governo do presidente Iván Duque e também denunciando a violência policial e o assassinato de ativistas de direitos humanos.

Entre 2006 e 2008, é possível notar um crescimento na rejeição aos partidos que pode ser interpretada também pela lógica responsiva do eleitorado, tanto aos protestos, quando consideramos o cenário no Chile com as manifestações dos Pinguins ${ }^{1}$, como pelos escândalos de corrupção envolvendo os partidos, tomando aqui o escândalo do mensalão no Brasil como exemplo. Apenas a Colômbia apresentou leve redução na rejeição aos partidos, fato que também corrobora com nossa análise ao constatar que nesse período a política e economia do país estava relativamente estável.

Além disso, quando observamos o período em destaque nesse artigo (2010 a 2018), é possível avaliar como o antipartidarismo caminhou junto aos ciclos de protestos. Em especial, a partir de 2014, o banco de dados nos permite ver um amplo salto na rejeição aos partidos políticos, o que corresponde ao ápice do que no Brasil ficou conhecido como Jornadas de Junho de 2013. No ano de 2016, os patamares de rejeição aos partidos alcançam seu auge dentro de um cenário de crise econômica e crítica às políticas neoliberais no Chile, enquanto no Brasil a política se via agitada pelo processo de impeachment da então presidenta Dilma Rousseff.

Nesse sentido, podemos compreender esse resultado a partir da perspectiva do antipartidarismo reativo proposto por Poguntke e Scarrow (1996). À medida que os protestos vão inserindo os jovens na vida política, estes vão adquirindo maior

1 Em maio de 2006 , os estudantes do ensino médio chileno protestaram diante de um cenário de descaso na educação, sendo escolas com problemas de infraestrutura um dos pontos das reinvindicações. Nesse contexto foram apelidados de pinguins (apelido que depois adotaram) por usarem um uniforme preto e branco que lembrava pinguins. 
percepção da atuação dos partidos e das suas falhas como canais de mediação, desenvolvendo sentimentos negativos em relação à atuação e à existência dos partidos. Assim, um antipartidarismo reativo se formaria nos jovens, alimentando também o antipartidarismo cultural ao perpetuar a imagem dos partidos como figuras desligadas da população e afeitos às práticas patrimonialistas, com vistas exclusivas a conquistar o poder do Estado.

No entanto, a percepção sobre os partidos não se relaciona somente com os protestos. Prova disso é que o Brasil, por exemplo, apesar de entrar mais tardiamente nas ondas de protestos em comparação ao Chile, já apresentava, em 2010, uma rejeição aos partidos superior à chilena. Esse dado nos indica que o processo de formação histórica dos partidos no Brasil - caracterizado por uma lógica elitista e refratária à participação popular - tem um impacto na percepção do eleitorado (BAQUERO, LINHARES, 2011; BAQUERO, VASCONCELOS, 2013).

Considerando que a descrença nos partidos políticos pode levar a um funcionamento precário das normas e leis, abrindo espaço para uma "desinstitucionalização da representação política” (BAQUERO, BAQUERO, MORAIS, 2016b), investigamos em que medida a concepção negativa dos jovens em relação aos partidos também se reflete na sua percepção sobre a democracia.

Gráfico 4: Concordância com a frase:

"A democracia é a melhor forma de governo" (\%)

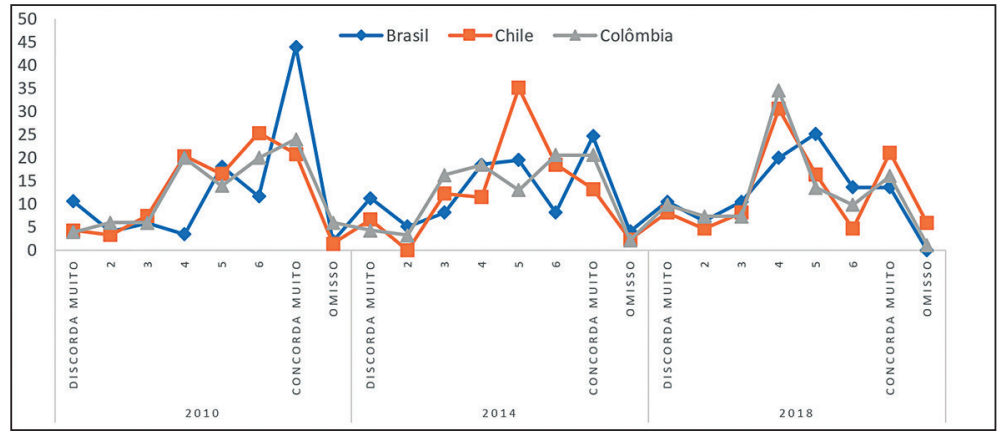

Fonte: Elaboração própria com base nos dados do Lapop de 2010, 2014 e 2018.

O Gráfico 4 nos apresenta como os jovens com tendências antipartidárias avaliam a democracia. Como podemos observar, no ano de 2010, houve uma clara tendência positiva em relação à democracia - no caso brasileiro, esse dado é especialmente evidente, alcançando $44 \%$ dos jovens antipartidários. No entanto, ainda com foco no Brasil, quando consideramos a faixa de tempo, é drástica a queda no apoio à democracia. A Colômbia apresentou uma evolução positiva no ano de 2014, mas também caiu consideravelmente em 2018. A preferência dos chilenos 
pela democracia se manteve nos patamares intermediários ao longo do período, o que, de um modo geral, começou a acontecer com os demais a partir de 2014. Essa tendência dos jovens se deslocarem às posições ambivalentes, conforme definição de Moisés (2008) quanto à concordância com a democracia enquanto melhor forma de governo, pode ser compreendida como um indício de que a percepção negativa sobre os partidos políticos, como instituição democrática, tem impactos sobre a percepção geral da legitimidade da democracia.

Nos anos em que tivemos o maior percentual de jovens com tendências antipartidárias $(2014,2018)$, a distribuição do apoio à democracia tendeu à ambivalência, ou seja, os jovens se colocaram numa posição intermediária de concordância que, se não chega a expressar desaprovação à democracia, tampouco exprime sua defesa, criando espaço para possibilidades autoritárias. Por outro lado, esse dado nos apresenta o caráter híbrido que a democracia possui para os jovens com tendências antipartidárias, ou seja, apesar de apoiarem o regime, eles não se identificam com as instituições democráticas, em especial, com os partidos, o que evidencia a fragilidade do sistema democrático.

Gráfico 5: Interesse por política (\%)

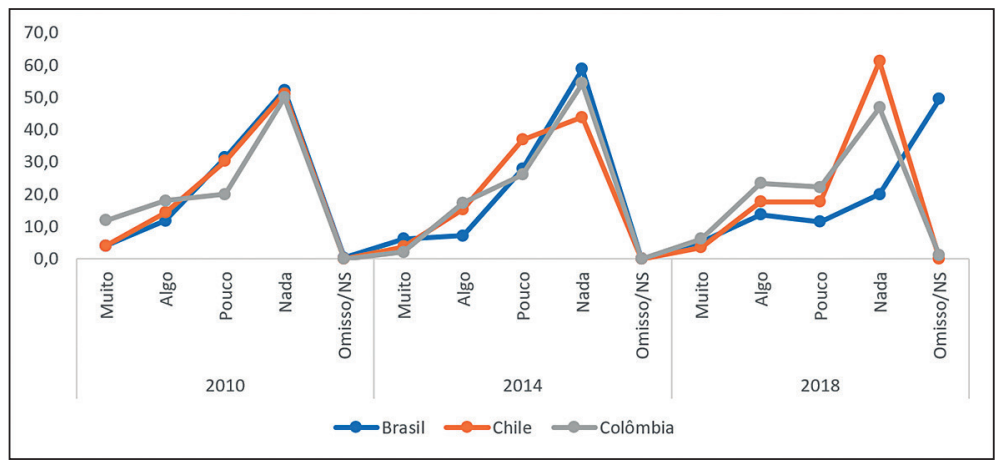

Fonte: Elaboração própria com base nos dados do Lapop 2010, 2014 e 2018.

Quanto ao interesse por política, o Gráfico 5 mostra que a política não é vista como algo atrativo pelos jovens. A variável "nada" é prevalente em todos os anos, ganhando destaque em 2014, com exceção do Chile, onde essa variável só assumiu a dianteira em 2018. Assumindo a perspectiva do antipartidarismo cultural, é compreensível o desinteresse pela política, especialmente em momentos de crise. Mas esses dados também refletem o antipartidarismo reativo, o qual, segundo Poguntke e Scarrow (1986), é resultado de uma sucessão de más experiências com os partidos políticos. 
Em suma, o antipartidarismo dos jovens tem relação com experiências negativas a respeito dos partidos - o que se explica pelo conceito de Poguntke e Scarrow (1996) de antipartidarismo reativo. Mas, o antipartidarismo dos jovens também se explica pelo conceito de antipartidarismo cultural (resultado do processo histórico de formação das democracias que levaria a uma baixa percepção do eleitor sobre a necessidade de existência dos partidos políticos). No caso, o antipartidarismo cultural se expressa pelo fato de ser um sentimento antigo relacionado à formação sociocultural dos países analisados.

Inicialmente, o desinteresse pela política entre os jovens poderia ser lido como um indicativo de decadência da democracia, ou indício de que o antipartidarismo seria o resultado da despolitização dos jovens; no entanto, gostaríamos de problematizar esses dados. Apesar dos baixos índices de interesse por política no gráfico, estudos têm evidenciado o engajamento dos jovens nos ciclos de protestos ocorridos nos últimos anos, bem como sua presença em movimentos sociais, nascidos ou inspirados em formas de organização mais fluídas, a exemplo do ocorreu nas Jornadas de Junho (PEREZ, 2019). Logo, não é possível afirmar que os jovens não se interessam pela política, mas sim que eles não se interessam pela política partidária, daí o número expressivo de antipartidários. Mas eles participam de organizações como os coletivos que têm como característica, justamente, o rechaço às instituições tradicionais, principalmente aos partidos políticos (PEREZ, 2019), além de organizarem e se expressarem em grandes protestos como as Jornadas de Junho de 2013, em que havia hostilidade também aos partidos (TATAGIBA, 2014).

\section{Conclusão}

O antipartidarismo é um fenômeno do comportamento político que tem se mostrado importante para a análise do comportamento eleitoral e para a questão da estabilidade democrática, tendo em vista a centralidade dos partidos nas democracias modernas. Ainda há muito a ser explorado sobre o tema do antipartidarismo entre os jovens, tanto no que se refere aos sentidos que o antipartidarismo pode assumir para esse público, quanto aos possíveis efeitos do antipartidarismo para o futuro da democracia.

Esta pesquisa procurou contribuir com o tema, inicialmente, apresentando um panorama dos sentimentos e percepções sobre os partidos políticos em jovens no Chile, Colômbia e Brasil, panorama este construído a partir do banco de dados do Lapop, considerando as ondas de 2006, 2008, 2010, 2012, 2014, 2016 e 2018. Diante de um cenário em que os partidos apresentam uma avaliação negativa por parte do eleitorado jovem, procuramos compreender mais detalhadamente os sentidos e percepções dos jovens sobre os partidos políticos. Constatamos que o 
antipartidarismo expresso pelos jovens se desenvolve concomitante à desilusão com os partidos políticos, a qual pode ser compreendida a partir do conceito de antipartidarismo reativo. Por outro lado, os grandes protestos que expressam e alimentam o contexto político têm relação com a percepção dos jovens a respeito dos partidos, reafirmando a importância do aspecto cultural na explicação do fenômeno.

Logo, diversos elementos têm que ser considerados para a compreensão do antipartidarismo entre os jovens como, a decepção deles com os partidos assim como a disseminação de protestos que têm, justamente, uma forte crítica a essas instituições.

Além disso, as percepções políticas dos jovens dos países estudados permitem considerar também o quanto as dinâmicas políticas e sociais na América Latina têm se desenvolvido de forma semelhante e o quanto carecemos de análises comparativas para construir um quadro mais completo dos processos políticos que permeiam o continente.

Nesse sentido, sugerimos pesquisas comparativas no sentido de captar o quanto o antipartidarismo explica e é explicado pelos protestos e mudanças nos contextos políticos latino-americanos e que ajudem a compreender suas relações com processos de consolidação ou ameaças aos sistemas democráticos.

\section{ANTIPARTISANSHIP AMONG YOUTH IN Brazil, Chile and Colombia}

ABSTRACT: The present research makes a comparative analysis on how antipartisanship feelings are manifested in the youths of Brazil, Chile and Colombia, countries which had important protest demonstrations with the participation of the young people since 2011. The perception of the youths on the political parties was analyzed based upon Lapop's database, considering the waves of 2006, 2008, 2010,2012, 2014, 20016 and 2018, with an emphasis on the years 2010, 2014 and 2018 - periods marked by cycles of protest demonstrations in the selected countries. The classification of the antipartisan youth was made based on the variables such as sympathy and trust towards political parties. To understand the perceptions of antipartisan youth, we analyze how much they support democracy and are interested in politics. The results demonstrate that antipartisanship in youth is manifested from reactive antipartisanship which is also related to socio-cultural and contextual aspects.

KEYWORDS: Antipartisanship. Youth. Democracy. Latin America. 


\section{EL ANTIPARTIDISMO ENTRE LOS JÓVENES de Brasil, Chile y Colombia}

RESUMEN: Esta investigación hace un análisis comparativo de las formas en que se manifiestan los sentimientos antipartidistas en los jóvenes de Brasil, Chile y Colombia, países que han tenido grandes protestas con participación juvenil desde 2011. La percepción de estos jóvenes sobre los partidos políticos fue analizada a partir de la base de datos Lapop, considerando las oleadas de 2006, 2008, 2010, 2012, 2014, 2016 y 2018, con énfasis en los años 2010, 2014 y 2018 -periodos marcados por ciclos de protestas en los países seleccionados. La clasificación de los jóvenes antipartidos se hizo en base a las variables simpatía y confianza por los partidos políticos. Para entender las percepciones de los jóvenes antipartidistas, analizamos en qué medida apoyan la democracia y se interesan por la política. Los resultados muestran que el antipartidismo en los jóvenes se manifiesta a partir de un antipartidismo reactivo relacionado también con aspectos socioculturales y contextuales.

PALABRAS CLAVE: Antipartidismo. Juventud. Democracia. América Latina.

\section{REFERÊNCIAS}

ALMOND, Gabriel; VERBA, Sidney. The civic culture. Newbury Park: Sage, 1989.

AUGUSTO, Acácio; ROSA, Pablo; RESENDE, Paulo Edgar. Capturas e resistências nas democracias liberais: uma mirada sobre a participação dos jovens nos novíssimos movimentos sociais. Estudos de Sociologia, Araraquara, n.40, v.21, p.21-37, jan.-jun. 2016.

BAQUERO, Marcello; BAQUERO, Rute. Novos padrões de participação política dos jovens na democracia brasileira? Em Debate, Belo Horizonte, n.8, v.4, p.19-25, nov. 2012.

BAQUERO, Marcello, BAQUERO, Rute; MORAIS, Jennifer A. Socialização política e internet na construção de uma cultura política juvenil no sul do Brasil. Educacão e Sociedade, Campinas n.137, v.37, p.989-1008, out-dez. 2016a.

BAQUERO, Marcello, BAQUERO, Rute; MORAIS, Jennifer A. Os jovens estão mais assertivos politicamente no Brasil? Uma análise da cultura política. Revista Debates, Porto Alegre, n.02, v.10, p.71-94, mai-ago. 2016b.

BAQUERO, Marcello; LINHARES, Bianca de Freitas. Por que os brasileiros não confiam nos partidos? Bases para compreender a cultura política (anti)partidária e possíveis saídas. Revista Debates, Porto Alegre, n.01, v.5, p.89-114, jan.-jun. 2011. 
BAQUERO, Marcello; MORAIS, Jennifer. A internet e a (des)politização dos jovens brasileiros. Revista Cadernos de Campo, Araraquara, n.25, p.33-62, jul.-dez. 2018.

BAQUERO, Marcello; VASCONCELOS, Camila. Crise de representação política, o surgimento da antipolítica e os movimentos apartidarismo no Brasil. Anais do V Congresso da Compolítica. GT Cultura política, comportamento e opinião pública. Curitiba, 2013, p.21.

BARDI, Luciano. Anti-party sentiment and party system change in Italy. European Journal of Political Research, Netherlands, n.03, v.29, p.345-363, abr. 1996.

BBC. O que move os protestos na Colômbia, mais um país latino-americano em onda de manifestações. Reportagem publicada em 23 de novembro de 2019. Disponível em: https:// www.bbc.com/portuguese/internacional-50533914. Acesso em: 10 mar. 2021.

BOGHOSSIAN, Cynthia; MINAYO, Maria Cecília. Revisão sistemática sobre juventude e participação nos últimos 10 anos. Saúde e Sociedade. São Paulo, n.03, v.18, p.411-423, mar. 2009.

BORBA, Julian; GIMENES, Éder; RIBEIRO, Ednaldo. A. Os determinantes do ativismo partidário na América Latina. Revista Latinoamericana de Opinión Pública, n. 5, p. 13-47, 2015a.

BORBA, Julian; GIMENES, Éder; RIBEIRO, Ednaldo. Bases sociais, atitudinais e comportamentais do apartidarismo Brasileiro. Novos Estudos CEBRAP, n.1, v.101, p.2755, mar. 2015b.

DALTON, Russel; MCALlister, Ian; WATtEnBERG, Marton. Democracia e identificação partidária nas sociedades industriais avançadas. Análise Social, n.167, v.38, p.295-320, 2003.

DIAS, Audrey. Sentimentos antipartidários e seus determinantes na América Latina em 2012. Revista Teoria \& Política, n.2, v.27, p.26-53, 2018.

FUKS, Mário. Efeitos diretos, indiretos e tardios: trajetórias da transmissão intergeracional da participação política. Lua Nova. São Paulo, nº3, p. 145-178, 2011.

FUKS, Mário; BORBA, Julian; RIBEIRO, Ednaldo. Polarização, Antipartidarismo e tolerância política no Brasil. Anais do $\mathbf{4 2}^{\circ}$ Encontro Anual da Anpocs. GT 05 Comportamento Político, Opinião Pública e Cultura Política. Caxambu, 2018, p.17.

FUKS, Mário; CASALECCHI, Gabriel. Quando confiar é bom? Repensando a confiança e desconfiança política no Brasil. Latin American Research Review, vol. 51, no. 2. p.217$232,2016$.

GIMENES, Éder. Eleitores e partidos políticos na América Latina. Curitiba: Appris, 2017. 
GIMENES, Éder. Comportamento eleitoral e tipologia da ação social weberiana: considerações sobre a tese do apartidarismo norte-americano. Em Tese. Florianópolis, n.1, v.11, p.109-132, jan.-jun. 2014.

GIMENES, Éder; BORBA, Julian. Adesão à Democracia e Apartidarismo na América Latina: Análise Multidimensional. Mediações. Londrina, n.3, v.24, p.167-183, set.-dez. 2019.

GOHN, Maria da Glória. Jovens na política na atualidade: uma nova cultura de participação. Caderno CRH. Salvador, nº 82, vol. 31, p.117-133, jan.-abr. 2018.

GOHN, Maria. Manifestações de protesto nas ruas no Brasil a partir de Junho de 2013: novíssimos sujeitos em cena. Revista Diálogo de Educação, Curitiba, n.47, v.16, p.125146, jan.-abr. 2016.

KRISCHKE, Paulo. Perfil da juventude brasileira: questões sobre cultura política e participação democrática. Revista Internacional Interdisciplinar-Interthesis. Florianópolis, n.2, v.1, p. 01-27, out. 2004.

MOISÉS, José. Cultura política, instituições e democracia - Lições da experiência brasileira. Revista Brasileira de Ciências Sociais, vol. 23, nº 66, p. 11-44, 2008.

MOYA, Julian; GALLARDO, Valeria. Una generación «sin miedo»: análisis de discurso de jóvenes protagonistas del movimiento estudiantil chileno. Última Década, n.51, v.27, p.225-257, jul. 2019.

NORRIS, Pippa. Critical citizens: global support for democratic government. Oxford University Press, 1999.

OKADO, Lucas; RIBEIRO, Ednaldo; LAZARE, Danilo. Partidarismo, ciclos de vida e socialização política no Brasil. Pro-Posições, n.1, v.29, p.267-295, jun.-dez. 2018.

OKADO, Lucas; RIBEIRO, Ednaldo. Condição juvenil e a participação política no Brasil. Paraná Eleitoral, n.01, v.04, p.53-78, fev. 2015.

PEREZ, Olívia C. Relação entre coletivos e as Jornadas de Junho. Opinião Pública. Campinas, SP, v. 25, n. 3, p.577-596, 2019.

POGUNTKE, Thomas. Anti-party sentiment - Conceptual thoughts and empirical evidence: Explorations into a minefield. European Journal of Political Research, Netherlands, v.29, p.319-344, 1996.

POGUNTKE, Thomas; SCARROW, Susan. The politics of anti-party sentiment: introduction. European Journal of Political Research, Netherlands, n.03, v.29, p.257-262, 1996.

RAMÍREZ, Liliana. Dinâmicas transnacionais em tempos de internet: jovens, mobilização e a apropriação do Facebook na Colômbia e no Brasil. Desidades, n.12, p.08-16, set. 2016. 
RIBEIRO, Ednaldo. Participação política e juventude: mudança no padrão de relacionamento entre os cidadãos e a política? Em Debate, Belo Horizonte, n.8, v.4, p26-34, nov. 2012.

RIBEIRO, Ednaldo; CARREIRÃO, Yan; BORBA, Julian. Sentimentos partidários e antipetismo: condicionantes e covariantes. Opinião Pública. Campinas, SP, v. 22, n.3, p.603-637, 2016.

RIBEIRO, Ednaldo; CARREIRÃO, Yan; BORBA, Julian. Sentimentos partidários e atitudes políticas entre os brasileiros. Opinião Pública. Campinas, SP, v.17, n. 2, p.333-368, 2011.

RIBEIRO, Ednaldo; FUKS, Mário. Tolerância política no Brasil. Opinião Pública. Campinas, SP, v. 25, n. 3, p. 531-555, 2019.

SAMUELS, David; ZUCCO, Cesar. Partisans, anti-partisans, and non-partisans: voting behavior in Brazil. New York: Cambridge University Press, 2018.

TATAGIBA, Luciana. 1984, 1992 e 2013: sobre ciclos de protestos e democracia no Brasil. Política \& Sociedade, v.13, n.28, p. 35-62, 2014.

VAN BIEZEN, Ingrid; MAIR, Peter; POGUNTKE, Thomas. Going, going...gone? The decline of party membership in contemporary Europe. European Journal of Political Research, n. 51, p. 24-56, 2012.

VEIGA, Luciana Fernandes; RIBEIRO Ednaldo; NICOLÁS, María Alejandra; BRAGATTO, Rachel Callai. El efecto de la experiencia democrática en la estructura de la legitimidad em América Latina y el Caribe. Opinião Pública. Campinas, SP, v. 23, n. 2, p.289-324, 2017.

VOMMARO, Pablo. Juventudes y políticas en la Argentina y en América Latina: tendencias, conflictos y desafios. Argentina: Grupo Editor Universitário, 2015.

Recebido em 16/02/2021.

Aprovado em 23/03/2021. 